\title{
DESENVOLVIMENTO DO FEIJOEIRO SOB O USO DE BIOFERTILIZANTE E ADUBAÇÃO MINERAL
}

\section{JÕ̃O A. GALBIATTI ${ }^{1}$, FLÁVIA G. DA SILVA ${ }^{2}$, CLAUDENIR F. FRANCO ${ }^{3}$, ANAIRA D. CARAMELO}

\begin{abstract}
RESUMO: A produção intensiva de alimentos exige manejo adequado do solo para garantir a produtividade e a sustentabilidade ambiental. Uma das alternativas é a utilização de resíduos orgânicos no desenvolvimento das culturas, diminuindo a dependência de adubos minerais. Com o objetivo de avaliar o desenvolvimento da cultura de feijão (Phaseolus vulgaris L.), utilizando biofertilizante e adubação mineral, conduziu-se o experimento com seis tratamentos dispostos ao acaso, em esquema fatorial, em quatro blocos, com parcelas de 8,0 x 5,0 m. Os tratamentos sob solo cultivado com a cultura de feijão caracterizaram-se como: com e sem biofertilizante (CB e SB, respectivamente) e para a adubação mineral foram utilizadas a dose recomendada no plantio, 1/2 dose de adubação e sem adubação mineral (AM, 1/2AM, SAM). Adotaram-se práticas culturais convencionais para o preparo inicial do solo, e em seguida foi efetuada a aplicação de biofertilizante de origem bovina na dosagem de $100 \mathrm{~m}^{3} \mathrm{ha}^{-1}$, com antecedência de três meses da semeadura. Foram avaliados os parâmetros massa da matéria seca acumulada na parte aérea da planta, área foliar e produtividade da cultura. Os resultados mostraram semelhanças entre as características analisadas, obtendo-se melhor desenvolvimento à cultura que recebeu biofertilizante.
\end{abstract}

PALAVRAS-CHAVE: biofertilizante, adubação orgânica, feijão, Phaseolus vulgaris.

\section{DEVELOPMENT OF BEAN WITH THE USE OF MINERAL FERTILIZATION AND BIOFERTILIZER}

\begin{abstract}
The intensive production requires appropriate management of soil to ensure the productivity and to avoid deterioration. One of the alternatives in improving the environmental quality in agriculture is the use of organic waste in the development of crops, reducing the dependence on mineral fertilizers. To evaluate the development of beans (Phaseolus vulgaris) using mineral fertilizer and biofertilizer, the experiment was conducted with six treatments randomly distributed in four blocks, with plots of $8.0 \times 5.0$ meters. The experimentation treatments were characterized as: with and without biofertilizer (WB e WOB, respectively), and for mineral fertilization it was used the recommended dose at planting, $1 / 2$ dosages and no mineral fertilization (MF, $1 / 2 \mathrm{MF}$, and WOMF). It was adopted conventional cultural practices to prepare the initial soil, followed by irrigation with bovine biofertilizer in dosage of $100 \mathrm{~m}^{3} \mathrm{ha}^{-1}$, three months ahead of sowing. It was evaluated the accumulated mass of the dry matter from different parts of the plant, leaf area and the culture productivity. The results showed similarities between the parameters examined, resulting in better development in the culture that received biofertilizer, either with the combination of half or equivalent amount of mineral fertilizer or only with the use of the effluent biodigester. The analysis of variance proved to be significant for the use of biofertilizer.
\end{abstract}

KEYWORDS: biofertilizer, organic fertilization, bean plant, Phaseolus vulgari.

\footnotetext{
${ }^{1}$ Eng $^{\circ}$ Agrônomo, Professor Doutor, FCAV/UNESP, Jaboticabal - SP, galbi@ @cav.unesp.br.

${ }^{2}$ Bióloga, Mestranda em Ciência do Solo, Departamento de Engenharia Rural, FCAV/UNESP, Jaboticabal - SP, flacgs@yahoo.com.br.

${ }^{3}$ Eng $^{\mathrm{O}}$ Agrônomo, Doutorando em Produção Vegetal, Departamento de Engenharia Rural, FCAV/UNESP, Jaboticabal - SP, cfafranco@ hotmail.com.

${ }^{4}$ Bióloga, Doutoranda em Ciência do Solo, Departamento de Engenharia Rural, FCAV/UNESP, Jaboticabal - SP, adcaramelo@hotmail.com. 


\section{INTRODUÇÃO}

O aumento da população requer, cada vez mais, produção de alimentos para suprir a demanda, sendo necessário aumentar a produtividade através do manejo adequado do solo, uma vez que o espaço territorial é limitado. A concentração de pessoas e animais gera grandes quantidades de resíduos por área que, quando não geridos de maneira correta, causam severos impactos ambientais.

Aliando produtividade com manejo de resíduos, surge a ideia de desenvolvimento sustentável através da agricultura orgânica. Nesse sistema, o controle de pragas e doenças é baseado na resistência da planta, obtida pelo equilíbrio nutricional, balanço energético e metabólico, e com o aumento na biodinâmica do solo (MEDEIROS et al., 2003).

A matéria orgânica no solo tem grande importância como fonte de nutrientes, na retenção de cátions, melhorando a atividade microbiana e as propriedades físicas do solo que influenciam na disponibilidade de ar e água às raízes das plantas (PELÁ, 2002). Interage com a fase mineral, interferindo na dinâmica de nutrientes, exercendo função importante na fertilidade do solo (MENDONZA et al., 2000). No modelo convencional de adubação, a matéria orgânica é vista como condicionador de solo (GUIMARÃES et al., 1999), e a quantidade e proporção das frações da mesma são utilizadas como indicadoras de qualidade dos solos, devido à forte interação das substâncias húmicas com o material mineral (FONTANA et al., 2001).

O biofertilizante, produto final da fermentação da matéria orgânica, atua nutricionalmente sobre o metabolismo vegetal, possui alta atividade microbiana e bioativa, sendo capaz de proporcionar maior proteção e resistência à planta contra agentes externos, além de atuar na ciclagem de nutrientes no solo (MEDEIROS et al., 2003). Promove melhoria nas propriedades físicas do solo, tornando-o mais solto, com menor densidade, estimula as atividades biológicas (OLIVEIRA, et al., 1986), reduz a acidez do solo devido à capacidade de retenção de bases, pela formação de complexos orgânicos e pelo desenvolvimento de cargas negativas (GALBIATTI et al., 1996).

O fluxo dos nutrientes que estão imobilizados na solução do solo é essencial para a manutenção da fertilidade nos sistemas orgânicos. Na forma líquida, o biofertilizante é assimilado com maior rapidez, tendo grande utilidade para culturas que necessitam de quantidade elevada de nutrientes em ciclo curto (BARROS \& LIBERALINO FILHO, 2008).

O feijoeiro (Phaseolus vulgaris) é uma cultura de grande importância pelo caráter econômico, e significado social, sendo consumido por toda a população brasileira (SOUZA et al., 2006). No entanto, apresenta produtividade baixa, decorrente de problemas associados a doenças de difícil controle, ao alto custo dos pesticidas e à precária situação financeira do pequeno produtor (agricultura familiar), que é responsável por mais de $67 \%$ da produção nacional. Possui ampla adaptação edafoclimática, o que permite seu cultivo durante todo o ano, em quase todos os estados brasileiros, mas apresenta baixa tolerância à deficiência hídrica e alta sensibilidade a diversas doenças, prejudicando o rendimento da cultura (DORNELLES, 2005).

Objetivou-se avaliar o desenvolvimento da cultura de feijoeiro (Phaseolus vulgaris L.), utilizando biofertilizante e adubação mineral.

\section{MATERIAL E MÉTODOS}

O trabalho foi desenvolvido no Departamento de Engenharia Rural da Faculdade de Ciências Agrárias e Veterinárias, Câmpus de Jaboticabal, da Universidade Estadual Paulista, localizado na latitude $21^{\circ} 15^{\prime \prime} 22^{\prime \prime} \mathrm{S}$ e longitude $48^{\circ} 18^{\prime} 58^{\prime \prime} \mathrm{W}$, com altitude média de $575 \mathrm{~m}$. O clima da região, segundo classificação de Köeppen, é do tipo Cwa, subtropical, relativamente seco no inverno, com chuvas no verão. O tipo de solo é o Latossolo Vermelho eutrófico típico, textura argilosa, A moderado, caulinítico apoférrico, relevo suave a ondulado (EMBRAPA, 2006). Na Tabela 1, mostram-se os dados médios da análise química do solo e do biofertilizante, referentes à massa seca, antes da instalação do experimento. 
TABELA 1. Dados médios da análise química do solo e do biofertilizante, antes da instalação do experimento. Data from chemical analysis of the soil and biofertilizer before the experiment setup.

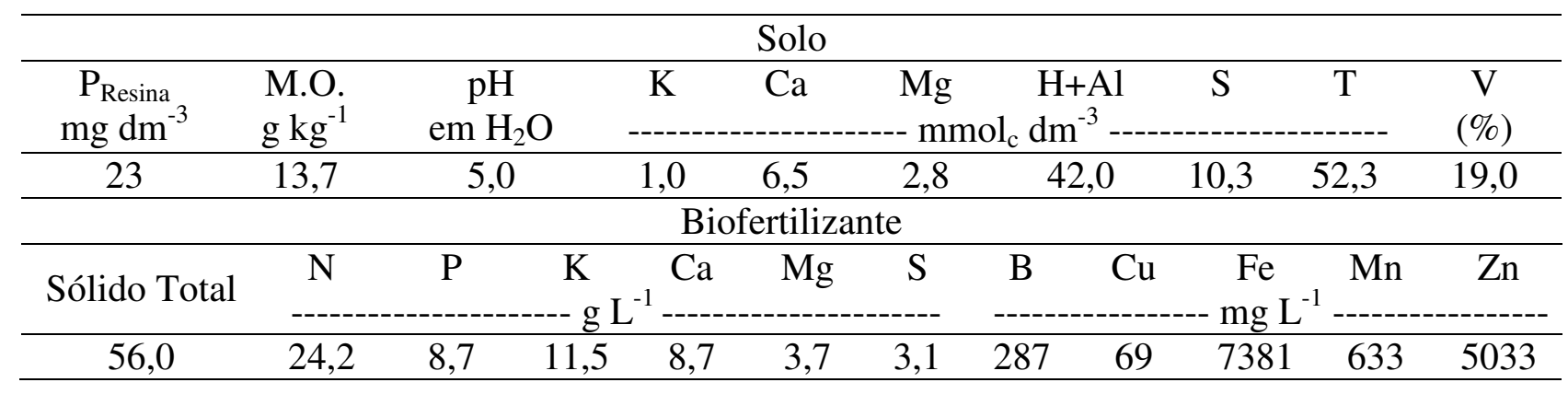

O delineamento experimental adotado foi o em blocos casualisados, com parcelas de $8,0 \times 5,0 \mathrm{~m}$, em esquema fatorial $2 \times 3$, com quatro repetições. Os tratamentos sob solo cultivado com a cultura de feijão IAC-Carioca caracterizaram-se como: com e sem biofertilizante (CB e SB, respectivamente) e para a adubação mineral foram utilizadas a dose recomendada no plantio, de acordo com RAIJ et al. (1997), 1/2 dose de adubação e sem adubação mineral (AM, 1/2AM, SAM, respectivamente).

Na condução do ensaio, adotaram-se práticas culturais convencionais para o preparo inicial do solo, e em seguida foi efetuada a aplicação nas parcelas estabelecidas, com biofertilizante de origem bovina, na dosagem de $100 \mathrm{~m}^{3}$ ha $^{-1}$ (OLIVEIRA et al., 1986) e com antecedência de três meses de semeadura da cultura de feijão. A aplicação do efluente de biodigestor foi realizada com regadores com capacidade de $18 \mathrm{~L}$, e o material orgânico foi incorporado ao solo através de uma gradagem.

O comportamento da matéria seca acumulada na parte aérea da cultura de feijoeiro foi avaliado através de amostragem semanal de seis plantas de cada parcela, colhidas ao acaso. As plantas foram lavadas, separadas em sacos plásticos e levadas à estufa de aeração forçada, a $70{ }^{\circ} \mathrm{C}$, onde permaneceram até adquirir peso constante. Em seguida, o material foi mantido em dessecadores até atingir o equilíbrio térmico com o ambiente, pesando-se em balança de precisão de 0,01 grama.

A massa de matéria seca total foi obtida a partir das massas secas parciais de caules, bainhas, folhas, flores e frutos.

A avaliação do desenvolvimento da área das lâminas foliares das plantas nos diversos tratamentos foi feita semanalmente, medindo-se o comprimento, no sentido da nervura principal, e a maior largura de 20 folhas colhidas ao acaso das plantas amostradas. O produto do comprimento pela largura de cada lâmina foliar foi multiplicado por um fator de correção igual a 0,70 para as folhas de formato cordiforme e a 0,59 para as demais folhas, segundo metodologia proposta por BENINCASA et al. (1976). A produção de grãos foi obtida colhendo-se todas as plantas de cada parcela. Com o peso dos grãos e o número de plantas colhidas, estimou-se a produção em $\mathrm{kg} \mathrm{ha}^{-1}$.

\section{RESULTADOS E DISCUSSÃO}

O uso de biofertilizante e da adubação mineral influenciou no crescimento das plantas, na massa seca das folhas, caule, pecíolo, parte aérea e área foliar, conforme mostram os resultados do teste F da Tabela 2. A interação entre o uso de biofertilizante e adubação mineral, no entanto, não foi significativa para o mesmo teste.

Os tratamentos utilizando biofertilizante apresentaram valores médios superiores em relação aos que não utilizaram para os quatro parâmetros avaliados, pelo teste de Tukey, a 5\%. Com relação à adubação mineral, observou-se que houve diferença estatística entre os valores médios de adubo mineral estudados, sendo que o melhor desempenho ocorreu com as plantas que receberam a dose completa recomendada. A aplicação de esterco suíno aumentou o rendimento da cultura do feijão- 
-vagem, mesmo na ausência de adubo mineral e, quando associado, antecipou o início da floração, tornando-o mais precoce (ARAUJO et al., 2001).

TABELA 2. Teste F, coeficiente de variação e valores médios de massa seca das folhas, caule, pecíolo, parte aérea e área foliar de feijão. F test, variation coefficient and mean values of dry mass from leaves, stems, petioles, shoot and leaf area of beans.

\begin{tabular}{|c|c|c|c|c|}
\hline Tratamento & $\begin{array}{l}\text { Massa seca das } \\
\text { folhas }(\mathrm{g})\end{array}$ & $\begin{array}{c}\text { Massa seca do caule e } \\
\text { pecíolo }(\mathrm{g})\end{array}$ & $\begin{array}{c}\text { Massa seca da parte } \\
\text { aérea }(\mathrm{g})\end{array}$ & $\begin{array}{l}\text { Área foliar } \\
\left(\mathrm{cm}^{2}\right)\end{array}$ \\
\hline \multicolumn{5}{|l|}{ Teste F } \\
\hline Biofertilizante (B) & $21,70 * *$ & $24,95 * *$ & $32,90 * *$ & $11,04 * *$ \\
\hline Adubação mineral (AM) & $6,30^{*}$ & $5,15^{*}$ & $7,29 * *$ & $3,96^{*}$ \\
\hline $\mathrm{B} \times \mathrm{AM}$ & $1,98 \mathrm{~ns}$ & $1,06 \mathrm{~ns}$ & $1,69 \mathrm{~ns}$ & $0,13 \mathrm{~ns}$ \\
\hline \multicolumn{5}{|l|}{$\overline{\text { Biofertilizante }}$} \\
\hline Sem & $2,36 \mathrm{~b}$ & $8,26 \mathrm{~b}$ & $10,63 b$ & $86,17 \mathrm{~b}$ \\
\hline Com & $3,75 \mathrm{a}$ & $13,83^{\mathrm{a}}$ & $17,58^{\mathrm{a}}$ & $118,53 \mathrm{a}$ \\
\hline \multicolumn{5}{|l|}{ Adubação Mineral } \\
\hline Sem & $2,37 \mathrm{~b}$ & $8,69 b$ & $11,07 b$ & $83,66 b$ \\
\hline $1 / 2$ Recomendada & $3,15 \mathrm{ab}$ & $11,42 \mathrm{ab}$ & $14,57 \mathrm{ab}$ & $107,29 \mathrm{ab}$ \\
\hline Recomendada & $3,66 \mathrm{a}$ & $13,02 \mathrm{a}$ & $16,68^{\mathrm{a}}$ & $116,11 \mathrm{a}$ \\
\hline C. V. $(\%)$ & 23,9 & 24,73 & 21,04 & 23,3 \\
\hline
\end{tabular}

Na Tabela 3, estão apresentados os valores de F para regressão da massa seca das folhas, caule e pecíolo, parte aérea e área foliar. $\mathrm{O}$ teste foi significativo para todos os tratamentos, a $1 \%$ de probabilidade.

TABELA 3. Valores de F para ajustes de regressão para a massa seca das folhas, caule e pecíolo, parte aérea e área foliar. $F$ values for regression adjustment for dry weight of leaves, stems and petioles, shoot and leaf area.

\begin{tabular}{|c|c|c|c|c|c|c|}
\hline Tratamentos & SB+SAM & $\mathrm{SB}+1 / 2 \mathrm{AM}$ & $\mathrm{SB}+\mathrm{AM}$ & $\mathrm{CB}+\mathrm{SAM}$ & $\mathrm{CB}+1 / 2 \mathrm{AM}$ & $\mathrm{CB}+\mathrm{AM}$ \\
\hline & \multicolumn{6}{|c|}{ Folhas } \\
\hline Teste F & $14,01 * *$ & $14,29 * *$ & $36,97 * *$ & $32,89 * *$ & $23,50 * *$ & $58,49 * *$ \\
\hline Regressão linear & $33,78 * *$ & $38,75 * *$ & $111,95 * *$ & $125,13 * *$ & $76,33 * *$ & $226,92 * *$ \\
\hline Regressão quadrática & $11,27 * *$ & $15,99 * *$ & $9,43 * *$ & $2,07 \mathrm{~ns}$ & $0,03 \mathrm{~ns}$ & $1,57 \mathrm{~ns}$ \\
\hline \multirow[t]{2}{*}{ C.V. } & 26,99 & 25,63 & 24,71 & 19,85 & 26,38 & 15,36 \\
\hline & \multicolumn{2}{|c|}{ Caule e pecíolos } & & & & \\
\hline Teste F & $171,11 * *$ & $224,29 * *$ & $94,75^{* *}$ & $90,67 * *$ & $119,91 * *$ & $74,57 * *$ \\
\hline Regressão linear & $462,50 * *$ & $691,91 * *$ & $276,70 * *$ & $270,26 * *$ & $344,08 * *$ & $229,93 * *$ \\
\hline Regressão quadrática & $165,56 * *$ & $140,45 * *$ & $72,87 * *$ & $76,53 * *$ & $102,07 * *$ & $58,12 * *$ \\
\hline \multirow[t]{2}{*}{ C.V. } & 21,3 & 15,6 & 26,2 & 28,0 & 24,7 & 29,8 \\
\hline & Parte aérea & & & & & \\
\hline Teste F & $110,50 * *$ & $62,96 * *$ & $61,98 * *$ & $73,44 * *$ & $127,19 * *$ & $99,36 * *$ \\
\hline Regressão linear & $323,51 * *$ & $211,28 * *$ & $200,60 * *$ & $241,98 * *$ & $387,50 * *$ & $334,97 * *$ \\
\hline Regressão quadrática & $74,22 * *$ & $15,22 * *$ & $26,66 * *$ & $39,18 * *$ & $75,55 * *$ & $49,19 * *$ \\
\hline \multirow[t]{2}{*}{ C.V. } & 20,25 & 21,90 & 24,92 & 24,42 & 19,47 & 20,65 \\
\hline & Área foliar & & & & & \\
\hline Teste F & $32,00 * *$ & $28,14^{* *}$ & $15,90 * *$ & $21,65^{* *}$ & $36,94 * *$ & $28,71 * *$ \\
\hline Regressão linear & $81,67 * *$ & $93,47 * *$ & $53,28 * *$ & $74,99 * *$ & $114,51 * *$ & $85,25 * *$ \\
\hline Regressão quadrática & $6,25^{*}$ & $1,41 \mathrm{~ns}$ & $1,16 \mathrm{~ns}$ & $0,01 \mathrm{~ns}$ & $0,01 \mathrm{~ns}$ & $1,21 \mathrm{~ns}$ \\
\hline C.V. & 19,29 & 18,45 & 24,82 & 22,44 & 17,66 & 18,42 \\
\hline
\end{tabular}


A massa seca das folhas para os tratamentos sem o uso de biofertilizante teve ajuste quadrático, enquanto os tratamentos com o uso do biofertilizante tiveram ajuste linear. Para a massa seca do caule, pecíolo e parte aérea, a curva foi representada pela regressão quadrática. Para a área foliar, o tratamento SB+SAM apresentou um ajuste quadrático, enquanto os demais foram representados por um ajuste linear.

As curvas de regressão para a massa seca das folhas, em função do tempo, estão dispostas na Figura 1.

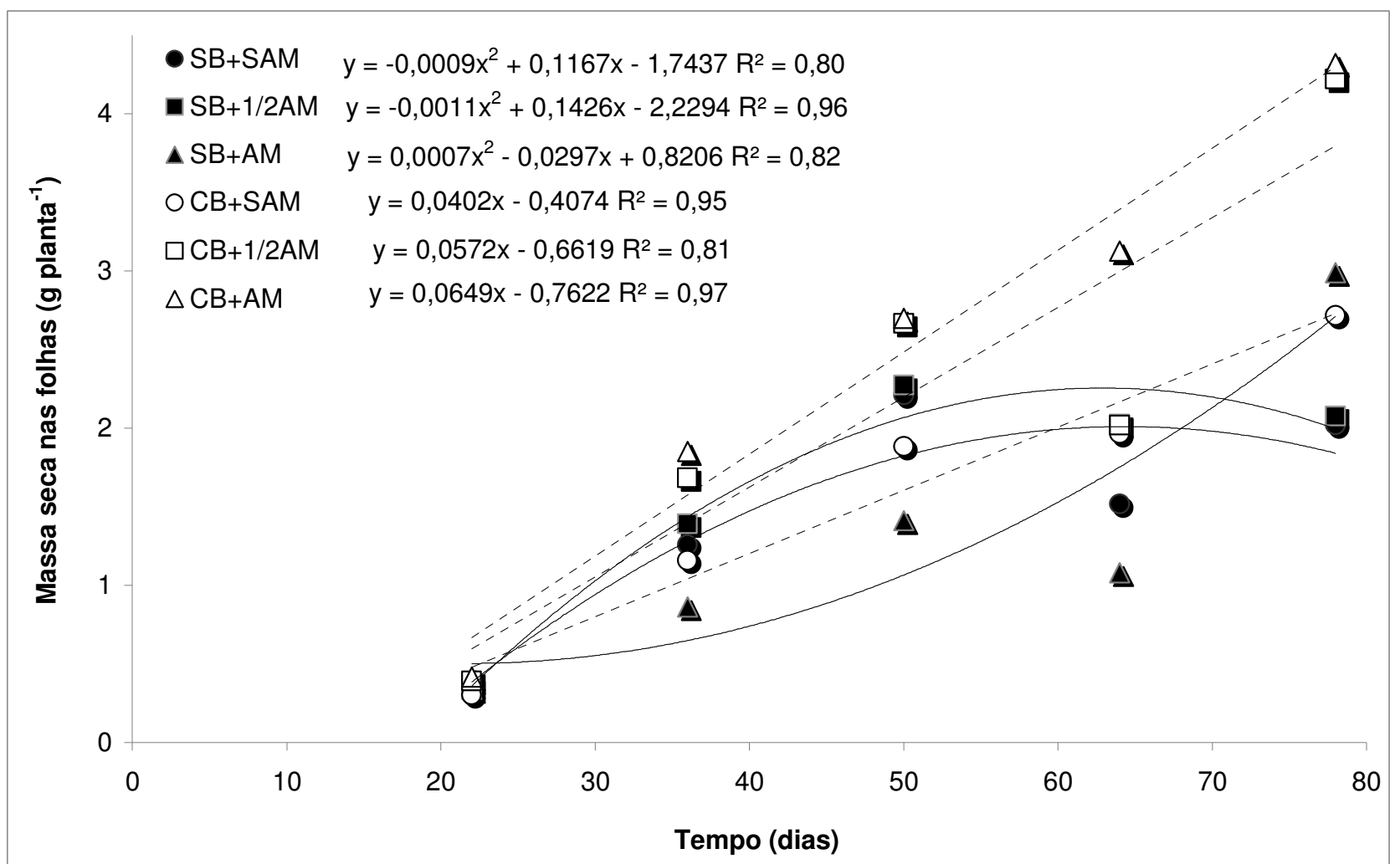

FIGURA 1. Massa seca acumulada nas folhas da planta de feijão em g planta $^{-1}$. Dry mass accumulated from bean leaves in g plant $^{-1}$.

Os tratamentos $\mathrm{CB}+\mathrm{SAM}, \mathrm{CB}+1 / 2 \mathrm{AM}$ e $\mathrm{CB}+\mathrm{AM}$ foram representados pela equação linear com aumento da massa seca, indicando que as plantas destes tratamentos tendem a apresentar maior massa ao longo do tempo. Esse comportamento pode ocorrer devido às propriedades do biofertilizante, que possui liberação lenta de nutrientes (FACHINI et al., 2004).

Os tratamentos $\mathrm{SB}+\mathrm{SAM}$ e $\mathrm{SB}+1 / 2 \mathrm{AM}$ foram representados pela equação quadrática, e as curvas mostram que o melhor desempenho ocorreu entre 55 e 65 dias após a semeadura com gradativa queda após este período. Para o tratamento SB+AM, observou-se um aumento da massa seca com o tempo.

O composto orgânico atua na otimização das propriedades físicas do solo, uma vez que a transformação da matéria orgânica em húmus potencializa a ação de microrganismos, resultando no melhor aproveitamento dos nutrientes do próprio solo, de maneira gradativa e contínua, resultando em maior equilíbrio nutricional para a cultura (PRIMAVESI, 1990).

A diminuição da matéria orgânica reduz a porosidade dos solos, a absorção e a capacidade de armazenamento de água e nutrientes, além de o sistema radicular das plantas encontrar dificuldades para se desenvolver, ficando as raízes restritas às camadas superficiais, comprometendo o crescimento e o desenvolvimento das culturas (EHLERS, 1994). 
As curvas de regressão para a massa seca do caule e do pecíolo em função do tempo estão dispostas na Figura 2. Todos os tratamentos foram representados pela equação quadrática com aumento da massa seca após 45 dias.

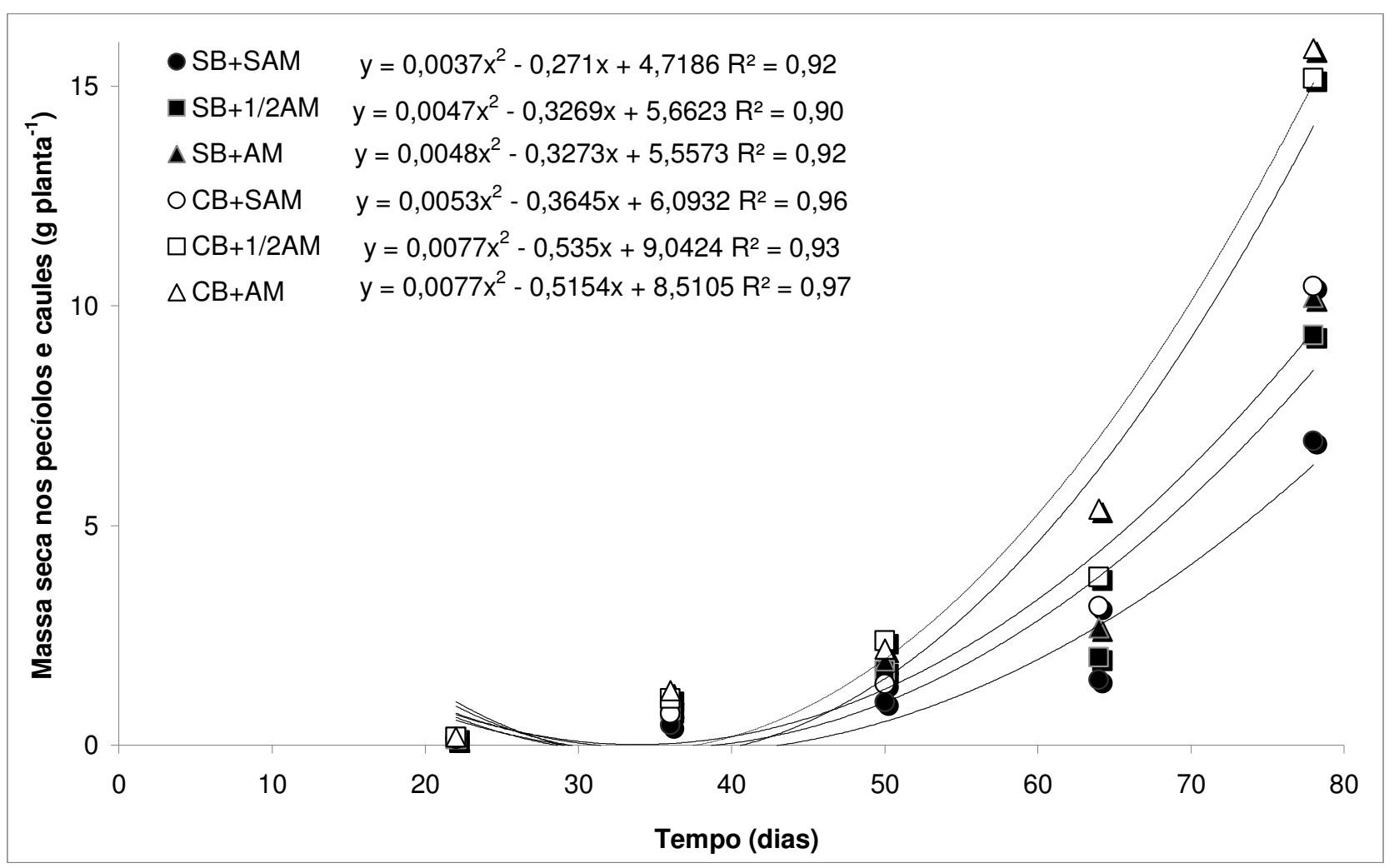

FIGURA 2. Massa seca acumulada no caule e no pecíolo da planta de feijão em g. Dry mass accumulated from beans stem and petiole in $\mathrm{g}$.

O manejo sustentável da matéria orgânica é fundamental para a manutenção da sua capacidade produtiva em longo prazo (CIOTTA et al., 2003). A substituição da adubação mineral por biofertilizante na cultura do maracujazeiro-amarelo provocou aumento do número de ramos em 32,5\% (COLLARD et al., 2001).

Esterco bovino e compostos naturais agem como condicionadores orgânicos, podendo ser superiores aos fertilizantes sintéticos, por melhorarem os atributos biológicos, físicos e químicos do solo, incrementando a produtividade das plantas (BULLUCK et al., 2002). No entanto, aplicações sucessivas de compostos orgânicos no solo podem causar efeitos negativos ao solo e às plantas (GALBIATTI et al., 2007).

As curvas de regressão para a massa seca da parte aérea, em função do tempo, estão dispostas na Figura 3.

Todos os tratamentos foram representados pela equação quadrática com aumento da massa seca após 40 dias, obedecendo às equações de regressão da Figura 3 com $\mathrm{R}^{2}$ superior a $90 \%$. 


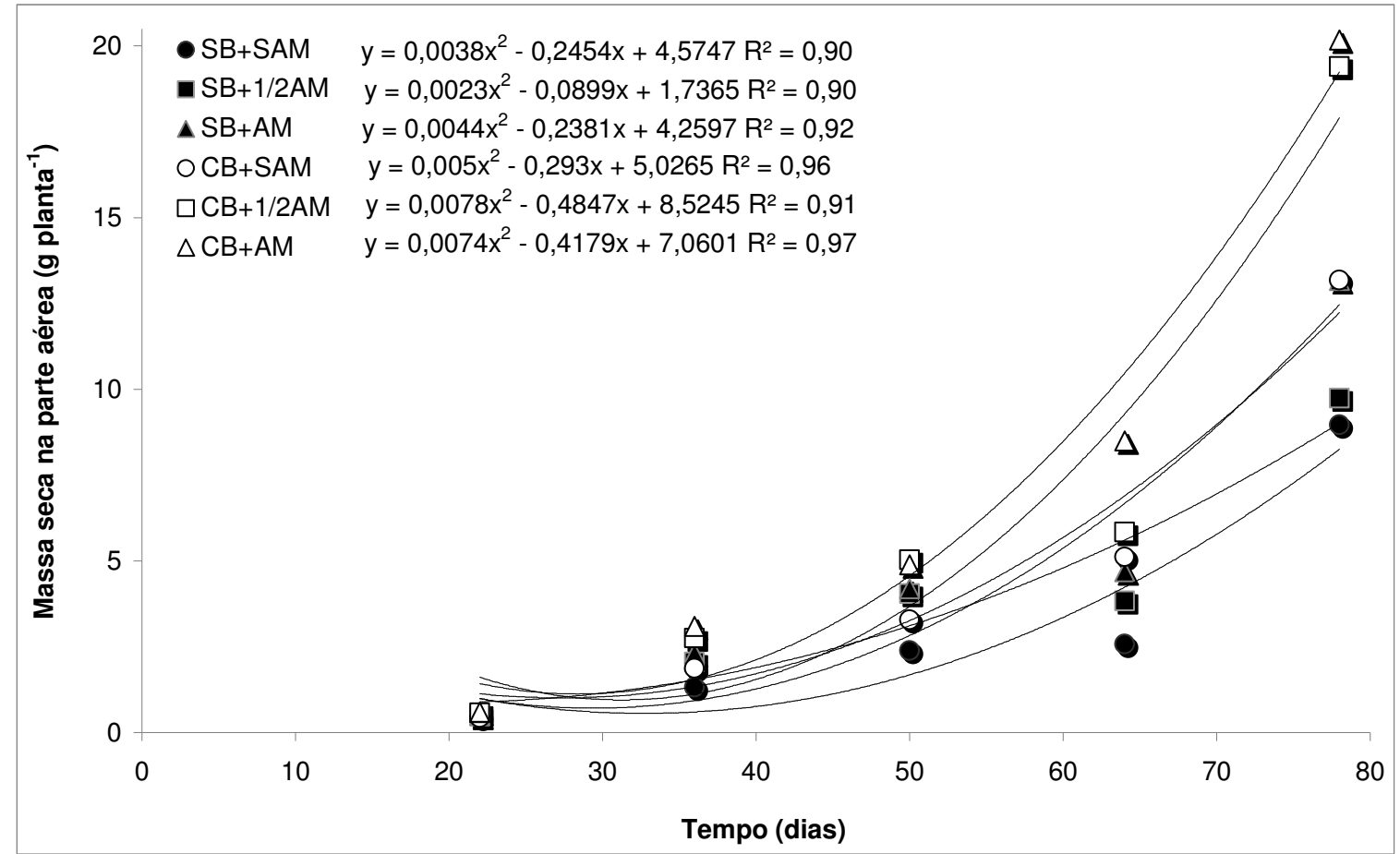

FIGURA 3. Massa seca acumulada na parte aérea da planta de feijão em g. Accumulated dry mass from shoots of beans plant in $\mathrm{g}$.

VILLELA JÚNIOR et al. (2007) utilizaram efluente de biodigestor proveniente da fermentação de esterco bovino como substrato e solução nutritiva no cultivo do meloeiro, obtendo crescimento vegetativo mais rápido, maior precocidade na colheita, frutos mais pesados e maior produtividade. A área foliar (Figura 4), assim como as massas secas avaliadas apresentaram comportamentos semelhantes, em que o melhor desempenho ocorreu nos tratamentos que receberam o biofertilizante.

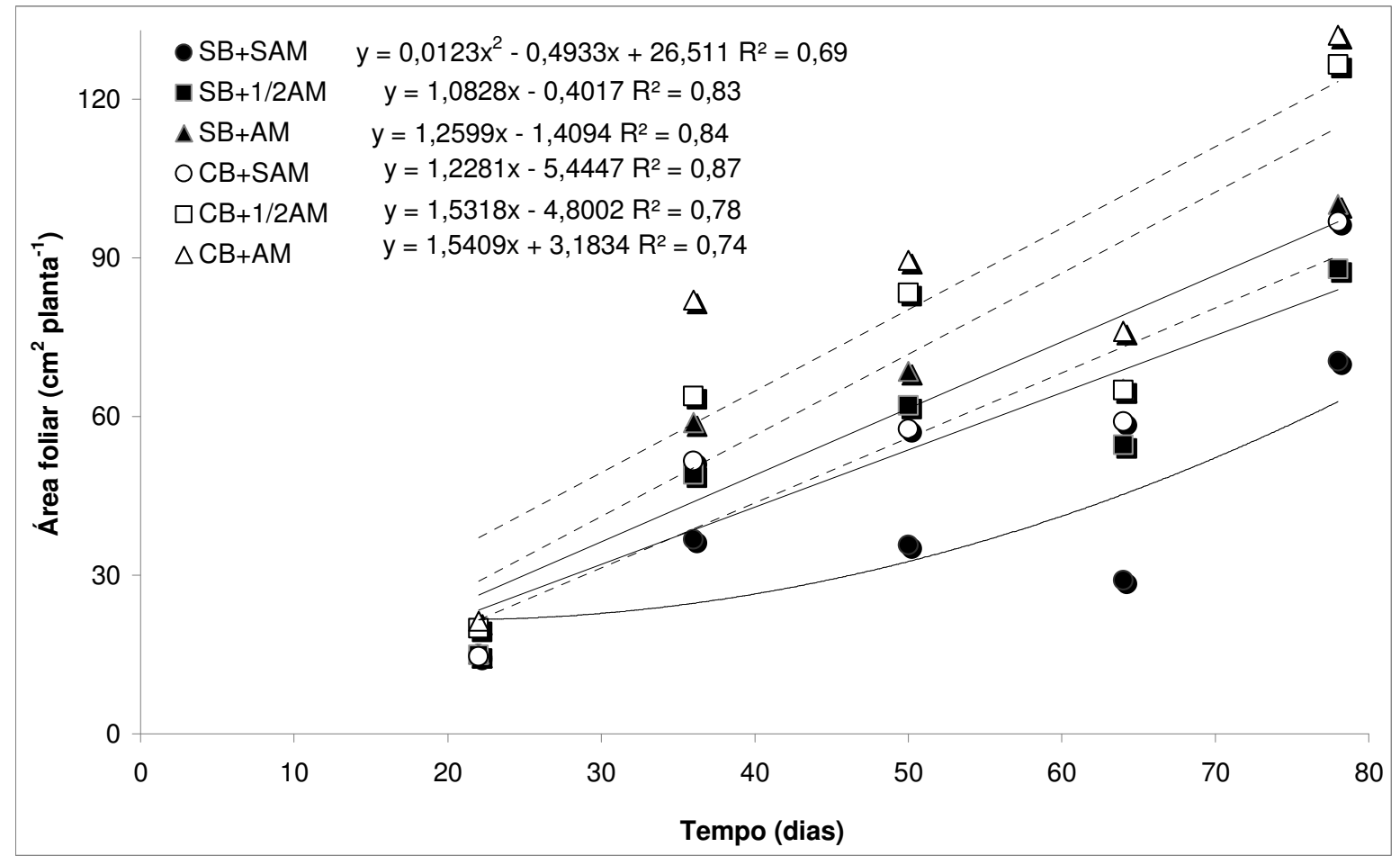

FIGURA 4. Área foliar durante o ciclo da cultura de feijão em $\mathrm{cm}^{2}$. Bean leaf area during the crop cycle in $\mathrm{cm}^{2}$. 
A produtividade foi influenciada pelo uso de biofertilizante e adubação mineral, e a interação biofertilizante $\mathrm{x}$ adubação mineral foi significativa. A produção e o número de plantas foram maiores com o uso de biofertilizante (Tabela 4). Como a produtividade é dependente da atividade fotossintética da planta, espera-se que plantas com maior área foliar sejam mais produtivas.

Comparados com o trabalho desenvolvido por SANTOS et al. (2007), os tratamentos com biofertilizante promoveram maiores médias de produtividade do feijão. Isto pode estar associado a um fornecimento equilibrado de macro e micronutrientes no ambiente radicular, que pode ter aumentado a absorção de água e nutrientes pelas plantas devido à maior área de contato das raízes com o biofertilizante.

TABELA 4. Teste $\mathrm{F}$, coeficiente de variação e valores médios de produção, número de plantas e produtividade de feijão. $\mathbf{F}$ test, variation coefficient and production mean values, plant numbers and yield of beans.

\begin{tabular}{|c|c|c|c|}
\hline Tratamento & $\begin{array}{l}\text { Produção } \\
\left(\text { g planta }^{-1}\right)\end{array}$ & $\begin{array}{l}\text { Número de plantas } \\
\left(\mathrm{ha}^{-1}\right)\end{array}$ & $\begin{array}{c}\text { Produtividade } \\
\left(\mathrm{kg} \mathrm{ha}^{-1}\right)\end{array}$ \\
\hline \multicolumn{4}{|l|}{ Teste F } \\
\hline Biofertilizante (B) & $22,52 * *$ & $12,49 * *$ & $19,06 * *$ \\
\hline Adubação mineral (AM) & $0,81 \mathrm{~ns}$ & $0,08 \mathrm{~ns}$ & $5,15 *$ \\
\hline $\mathrm{B} \times \mathrm{AM}$ & $0,95 \mathrm{~ns}$ & $1,13 \mathrm{~ns}$ & $4,37 *$ \\
\hline \multicolumn{4}{|l|}{ Biofertilizante } \\
\hline Sem & $2,16 b$ & $330.625 a$ & $710,31 b$ \\
\hline Com & $3,69 \mathrm{a}$ & $268.264 b$ & $934,92 \mathrm{a}$ \\
\hline \multicolumn{4}{|l|}{ Adubação Mineral } \\
\hline Sem & $2,76 \mathrm{a}$ & $298.854 a$ & $757,37 b$ \\
\hline 1/2 Recomendada & $2,81 \mathrm{a}$ & $295.417 a$ & $771,36 b$ \\
\hline Recomendada & $3,22 \mathrm{a}$ & $304.062 \mathrm{a}$ & $939,10 \mathrm{a}$ \\
\hline C. V. $(\%)$ & 27,0 & 14,43 & 15,32 \\
\hline
\end{tabular}

Os tratamentos utilizando biofertilizante apresentaram valores médios superiores em relação aos outros para produção e produtividade, pelo teste de Tukey, a 5\%. Com relação à adubação mineral, observou-se que houve diferença estatística entre os valores médios estudados apenas para a produtividade, sendo que o melhor desempenho ocorreu com as plantas que receberam a dose completa recomendada.

Os tratamentos que receberam biofertilizante e o tratamento com apenas a dose completa de adubação mineral, foram estatisticamente iguais e melhores que os tratamentos $\mathrm{SB}+1 / 2 \mathrm{AM}$ e SB+SAM, como mostra a Tabela 5, através da análise de variância.

TABELA 5. Médias da produtividade do feijoeiro $\left(\mathrm{kg} \mathrm{ha}^{-1}\right)$ resultante do desdobramento da interação entre o uso do biofertilizante e a adubação mineral. Average bean yield (kg $\mathrm{ha}^{-1}$ ) from the outspread of the interaction between the use of mineral fertilizers and biofertilizers.

\begin{tabular}{lcc}
\hline \multirow{2}{*}{ Adubação Mineral } & \multicolumn{2}{c}{ Biofertilizante } \\
\cline { 2 - 3 } & Sem Biofertilizante & Com Biofertilizante \\
\hline Sem & $558,45 \mathrm{~b}$ & $926,30 \mathrm{a}$ \\
$1 / 2$ Recomendada & $608,13 \mathrm{~b}$ & $934,60 \mathrm{a}$ \\
Recomendada & $934,35 \mathrm{a}$ & $943,85 \mathrm{a}$ \\
\hline
\end{tabular}

Médias seguidas de letras diferentes, na mesma linha ou coluna, diferem entre si, pelo teste Tukey $(\mathrm{p}<0,05)$. 
O uso agrícola dos solos, com a utilização de métodos de preparo com intenso revolvimento e sistemas de cultivos com baixa adição de resíduos vegetais, tem provocado a redução no conteúdo de matéria orgânica e a degradação química, física e biológica, reduzindo sua produtividade (PELÁ, 2005).

Estudos demonstram a eficácia da aplicação do biofertilizante na produtividade. VIANA et al. (2003) cultivaram cenoura com diferentes tratamentos (adubação verde, composto orgânico e biofertilizante), obtendo melhor resultado com a aplicação do biofertilizante. Também observaram que utilizando via foliar favoreceu o desenvolvimento vegetativo e, quando aplicado via solo, ocorreu maior produção das raízes. Maior rendimento de frutos do pimentão foi verificado por PAES (2003), pela aplicação de biofertilizante à base de urina de vaca. BEZERRA et al. (2008) avaliaram os efeitos de concentração e intervalos de aplicação de biofertilizante na produção de milho e verificaram melhor desempenho com a aplicação de biofertilizante na concentração de $20 \mathrm{~mL} \mathrm{~L}^{-1}$, com maior evidência no número de espigas por planta, e melhor desempenho no crescimento em intervalo de 15 dias de aplicação de biofertilizante. KONZEN \& ALVARENGA (2005) observaram que a aplicação isolada ou combinada de biofertilizante com adubação química proporcionou aumento na produção de milho forrageiro e milho grão. Dejetos líquidos de suínos foram utilizados em diferentes dosagens para verificar os efeitos na produtividade da cana-de-açúcar. A dosagem de $40 \mathrm{~m}^{3} \mathrm{ha}^{-1}$ equivaleu à adubação química, sendo que maiores dosagens apresentaram produtividades agrícolas superiores, aumentos de $76,5 \%$ a $96,3 \%$ em relação à testemunha, que foi de 58,10 $\mathrm{tha}^{-1}$ (LEITE et al., 2009).

\section{CONCLUSÕES}

A massa de matéria seca acumulada nas folhas, caule e pecíolo, na parte aérea, e a área foliar foram maiores nos tratamentos que receberam biofertilizante.

A melhor produtividade foi obtida nos tratamentos que receberam o efluente de biodigestor à base de esterco bovino.

A interação biofertilizante $\mathrm{x}$ adubação mineral para a produtividade foi significativa, indicando não haver diferença estatística entre o uso de biofertilizante com diferentes dosagens de adubação mineral e o tratamento com apenas a adubação mineral na dose completa.

\section{REFERÊNCIAS}

ARAUJO, J.S.; OLIVEIRA, A.D.P.; SILVA, J.A.L.; RAMALHO, C.I.; NETO, F.L.C. Rendimento do feijão-vagem cultivado com esterco suíno e adubação mineral. Revista Ceres, Viçosa-MG, v.48, n.278, p.501-510, 2001.

BARROS, L.E.O.; LIBERALINO FILHO, J. Composto orgânico sólido e em suspensão na cultura do feijão-mungo-verde (Vigna radiatal, wilkzeck). Revista Verde, Mossoró, v.3, n.1, p.114-122, 2008.

BENINCASA, M.M.P.; BENINCASA, M.; LATANZE, R.J.; JUNGUETTI, M.T.G. Métodos não destrutivos para estimativa da área folicular de Phaseolus vulgaris L. (feijoeiro). Cientifica, Jaboticabal, v.4, n.1, p.43-48, 1976.

BEZERRA, L.L.; SILVA FILHO, J.H.; ANDRADE, D. F. R.; MADALENA, J.A.S. Avaliação da aplicação de biofertilizante na cultura do milho: crescimento e produção. Revista Verde, Mossoró, v.3, n.3, p.131-139, 2008.

BULLUCK, L.R.; BROSIUS, M.G.; EVANYLO, K.; RISTAINO, J.B. Organic and synthetic fertility amendments influence soil microbial, physical and chemical properties on organic and conventional farms. Applied Soil Ecology, Amsterdam, v.19, n.2, p.147-160, 2002. 
CIOTTA, M.N.; BAYER, C.; FONTOURA, S.M.V.; ERNANI, P.R.; ALBUQUERQUE, J.A. Matéria orgânica e aumento da capacidade de troca de cátions em solos com argila de atividade baixa sob plantio direto. Ciência Rural, Santa Maria, v.33, n.6, p.1.161-1.164, 2003.

COLLARD, F.H.; ALMEIDA, A.; COSTA, M.C.R.; ROCHA, M.C. Efeito do uso de biofertilizante Agrobio na cultura do maracujazeiro-amarelo (Passiflora edulis f. flavicarpa Deg) Revista Biociências, Taubaté, v.7, n.1, p.15-21, 2001.

DORNELLES, M.S. Avaliação do estado nutricional e do controle da mancha angular em feijoeiro pulverizado com biofertilizantes líquidos. 2005. $133 \mathrm{f}$. Tese (Doutorado em Produção Vegetal) Universidade Estadual do Norte Fluminense Darcy Ribeiro, Campos de Goytacazes, 2005.

EHLERS, E.M. O que se entende por agricultura sustentável? 1994. 161 f. Dissertação (Mestrado em Ciência Ambiental) - Universidade de São Paulo, São Paulo, 1994.

EMBRAPA. EMPRESA BRASILEIRA DE PESQUISA AGROPECUÁRIA. Centro Nacional de Pesquisa de Solos. Sistema brasileiro de classificação de solos. 2. ed. Rio de Janeiro, 2006. 306 p.

FACHINI, E.; GALBIATTI, J.A.; PAVANI, L.C. Níveis de irrigação e de compostos de lixo orgânico na formação de mudas cítricas em casa de vegetação. Engenharia Agrícola, Jaboticabal, v.24, n.3, p.578-588, 2004.

FONTANA, A.; PEREIRA, M.G.; NASCIMENTO, G.B.; ANJOS, L.H.C.; EBELING, A.G. Matéria orgânica em solos de tabuleiros na Região Norte Fluminense-RJ. Floresta e Ambiente, Rio de Janeiro, v.8, n.1, p.114-119, 2001.

GALBIATTI, J.A.; GARCIA, A.; SILVA, M.L.; MASTROCOLA, M.A.; CALDEIRA, D.S.A. Efeitos de diferentes doses e épocas de aplicação de efluente de biodigestor e da adubação mineral em feijoeiro-comum (Phaseolus vulgaris L.) submetido a duas lâminas de água por irrigação por sulco. Científica, Jaboticabal, v.24, n.1, p.63-74, 1996.

GALBIATTI, J.A.; LUI, J.J.; SABORANO, D.Z.; BUENO, L.F.; SILVA, V.L. Formação de mudas de eucalipto com utilização de lixo orgânico e níveis de irrigação calculados por dois métodos. Engenharia Agrícola, Jaboticabal, v.27, n.2, p.445-455, 2007.

GUIMARÃES, P. T. G. et al. Cafeeiro. In: RIBEIRO, A. C.; GUIMARÃES, P. T. G.; ALVAREZ, V.H. (Eds.). Recomendações para o uso de corretivos e fertilizantes em Minas Gerais: $5^{\mathbf{a}}$ aproximação. Viçosa-MG: CSFSEMG/ UFV, 1999. p.289-302.

KONZEN, E.A.; ALVARENGA, R.C. Manejo e utilização de dejetos animais: aspectos agronômicos e ambientais. Sete Lagoas: EMBRAPA/ CNPMS, 2005. 16 p. (Circular Técnica, 63). Disponível em: <www.cnpsa.embrapa.br/down.php?tipo=publicacoes\&cod_publicacao=574>. Acesso em: 17 jun. 2008.

LEITE, G.F.; CUNHA NETO, F.R.; RESENDE, A.V. Produtividade agrícola da cana-de-açúcar adubada com dejetos líquidos de suínos. Ciência e Agrotecnologia, Lavras, v.33, n.1, p.132-138, 2009.

MEDEIROS, M.B.; WANDERLEY, P.A.; FRANKLIN, F.; FERNANDES, F.S.; ALVES, G.R.; DANTAS, P.; CORDÃO, R.P.; XAVIER, W.M.R.; LEAL NETO, J.S. Uso de biofertilizantes líquidos no manejo ecológico de pragas agrícolas. In: ENCONTRO TEMÁTICO MEIO AMBIENTE E EDUCAÇÃO AMBIENTAL DA UFPB, 2., 2003, João Pessoa. Anais... João Pessoa, 2003. p.19-23. Disponível em: <www.prac.ufpb.br/anais/meae/Anais_II_Encontro_ Tematico/trabalhos/BIOFERTILIZANTES.doc>. Acesso em: 20 jun. 2008.

MENDONZA, H.N.S.; LIMA, E.; ANJOS, L.H.C.; SILVA, L.A.; CEDDIA, M.B.; ANTUNES, M.V.M. Propriedades químicas e biológicas de solo de Tabuleiro cultivado com cana-de-açúcar com e sem queima da palhada. Revista Brasileira de Ciência do Solo, Campinas, v.24, p.201-207, 2000 . 
OLIVEIRA, I. P.; SOARES, M.; MOREIRA, J.A.A.; ESTRELA, M. F. C.; DAL'ACQUA, F.M.; PACHECO FILHO, O. Resultados técnicos e econômicos da aplicação de biofertilizante bovino nas culturas de feijão, arroz e trigo. Goiânia: EMBRAPA-CNPAF, 1986. 24 p. (Circular Técnica, 21). Disponível em: <www.cnpaf.embrapa.br/publicacao/circulartecnica/anteriores.htm>. Acesso em: 17 jun. 2008.

PAES, R.A. Rendimento do pimentão (Capsicum annuum L.) cultivado com urina de vaca e adubação mineral. 2003. 65 f. Dissertação (Mestrado) - Universidade Federal da Paraíba, Areia, 2003.

PELÁ, A. Efeito de adubos orgânicos provenientes de dejetos de bovinos confinados nos atributos físicos e químicos do solo e na produtividade do milho. 2005. $145 \mathrm{f}$. Tese (Doutorado em Agronomia) - Universidade Estadual Paulista, Faculdade de Ciências Agronômicas, Botucatu, 2005.

PELÁ, A. Uso de plantas de cobertura em pré-safra e seus efeitos nas propriedades físicas do solo e na cultura do milho em plantio direto na região de Jaboticabal-SP. 2002.53 f. Dissertação (Mestrado em Agronomia) - Universidade Estadual Paulista, Faculdade de Ciências Agrárias e Veterinárias, Jaboticabal, 2002.

PRIMAVESI, A. Manejo ecológico do solo: a agricultura em regiões tropicais. 9.ed. São Paulo: Nobel, 1990. 549 p.

RAIJ, B. van; CANTARELLA, H.; QUAGGIO, J.A.; FURLANI, A.M.C. (Ed.). Recomendações de adubação e calagem para o Estado de São Paulo. 2.ed. Campinas: Instituto Agronômico/Fundação IAC, 1997. 285 p. (Boletim Técnico, 100).

SANTOS, J.F.; LEMOS, J.N.R.; NÓBREGA, J.Q.; GRANGEIRO, J.I.T.; BRITO, L.M.P.; OLIVEIRA, M.E.C. Produtividade de feijão-caupi utilizando biofertilizante e uréia. Tecnologia \& Ciência Agropecuária, João Pessoa, v.1, n.1, p.25-29, 2007.

SOUZA, R.F.; FAQUIM, V.; FERNANDES, L.A.; AVILA, F.W. Nutrição fosfatada e rendimento do feijoeiro sob influência da calagem e adubação orgânica. Ciência e Agrotecnologia, Lavras, v.30, n.4, p.656-664, 2006.

VIANA, J.V. et al. Produção de cenoura (Daucus carota L.) sob diferentes fontes de adubação. In: CONGRESSO BRASILEIRO DE OLERICULTURA, 43., 2003, Recife. Resumo... Recife: SOB, 2003, p.23.

VILLELA JÚNIOR, L.V.E.; ARAÚJO, J.A.C.; BARBOSA, J.C.; PEREZ, L.R.B. Substrato e solução nutritiva, desenvolvidos a partir de efluente de biodigestor para cultivo do meloeiro. Revista Brasileira de Engenharia Agrícola e Ambiental, Campina Grande, v.11, n.2, p.152-158, 2007. 